\title{
SIRINGOHIDROMIELOGRAFIA INCIDENTAL
}

\author{
REGISTRO DE UM CASO
}

\author{
MANOEL JACOBSEN TEIXEIRA * \\ HELIO A. PEREIRA LEITAO FILHO *** \\ JOSE ZACLIS ** \\ GILBERTO MACHADO DE ALMEIDA ** \\ ANTONIO F. YUNES SALLES ****
}

O diagnóstico radiológico dos cistos intramedulares tem preocupado os neurologistas desde que essa entidade foi descrita, há 400 anos 26 . Somente nas últimas décadas é que foram introduzidos e padronizados os procedimentos neurorradiológicos para o estudo da siringomielia e da hidromielia; radiografias simples de crânio e de coluna vertebral, perimielografia com contrastes radiopacos, perimielografia gasosa, ventriculografia, tomografia axial por computação e a combinação de todos êles. São raras, entretanto, as publicações sobre a contrastação percutânea da cavidade siringomiélica 5,14,26,40. O objetivo do presente trabalho é o de apresentar os achados radiológicos de uma siringomielocistografia obtida acidentalmente durante a realização de perimielografia em doente com mielomeningomielocele lombar.

\section{OBSERVAÇAO}

C.R.S. - Doente com 5 anos de idade, do sexo masculino, atendido na Clínica Neúrológica do Hospital das Clínicas da USP, com 5 meses de deficit motor progressivo nos membros inferiores. Apresentava, desde o nascimento, tumor de consistêncía endurecida na região lombar. Havia história de retardo para inicio de deambulação e ausência de controle esfincteriano fecal e urinário. Ao exame notava-se: paraparesia crural flácida e área de cicatriz de forma circular medindo $4 \mathrm{~cm}$. de diâmetro, com limites irregulares, localizada na transição lombo-sacral. O estudo radiológico simples da coluna vertebral revelou que a $5^{\mathbf{a}}$ vértebra lombar era bífida e que o canal vertebral lombar e cervical apresentava-se moderadamente alargado. Com a finalidade de diagnosticar lesão intrarraqueana qLe pudesse contribuir para o agravamento progressivo do quadro neurológico, o estudo perimielográfico foi realizado por meio de punção lombar nos interespaços L3-L4. O líquido obtido pela punção era límpido, incolor e normotenso, e 5 cc de Lipiodol ultrafluido foram injetados. A radiografia revelou a presença de lojas superpostas contendo contraste radiopaco, com dimensóes variadas, septadas transversalmente, dispostas de modo mais ou menos regular ao longo de toda a medula espinal, e alcançando maior volume na região

Trabalho da Clínica Neurológica da FMUSP: *Assistente; ** Livre Docente; *** Neurorradiologista; **** Residente. 
torácica (Fig. 1). 0 limite superior destas lojas encontrava-se na transição bulbo-medular e o inferior ao nivel da mielomeningocele.

Com o diagnóstico de siringomielia o doente foi submetido a craniectomia de fossa posterior e à oclusão do óbex com músculo, segunđo a técnica proposta por Gardner 16. Houve melhora lenta e progressiva do quadro neurológico, tendo o paciente voltado a deambular sem auxilio.

As radiografias simples da colvna vertebral realizadas no período pós-operatório, revelaram que restava pequena quantidade de contraste na cavidade siringomiélica, uma vez que o maior volume havia escoado para o interior da cavidade da meningomielocele (Fig. 2).

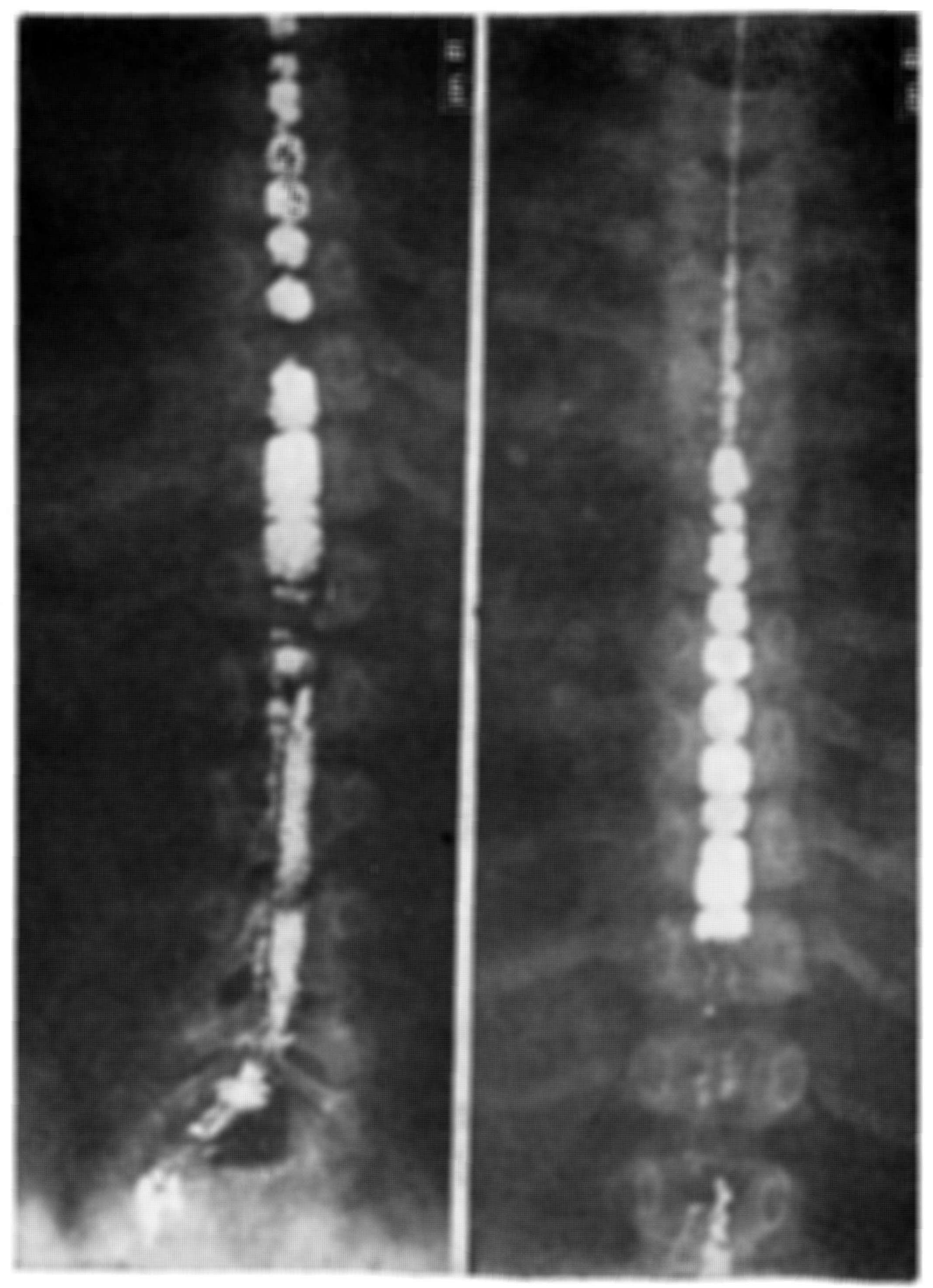

Fig. 1 - Caso C.R.S. - Aspecto da siringomielografia direta com o doente em posição erecta (A) e na posicão de Trendelemburg (B). 


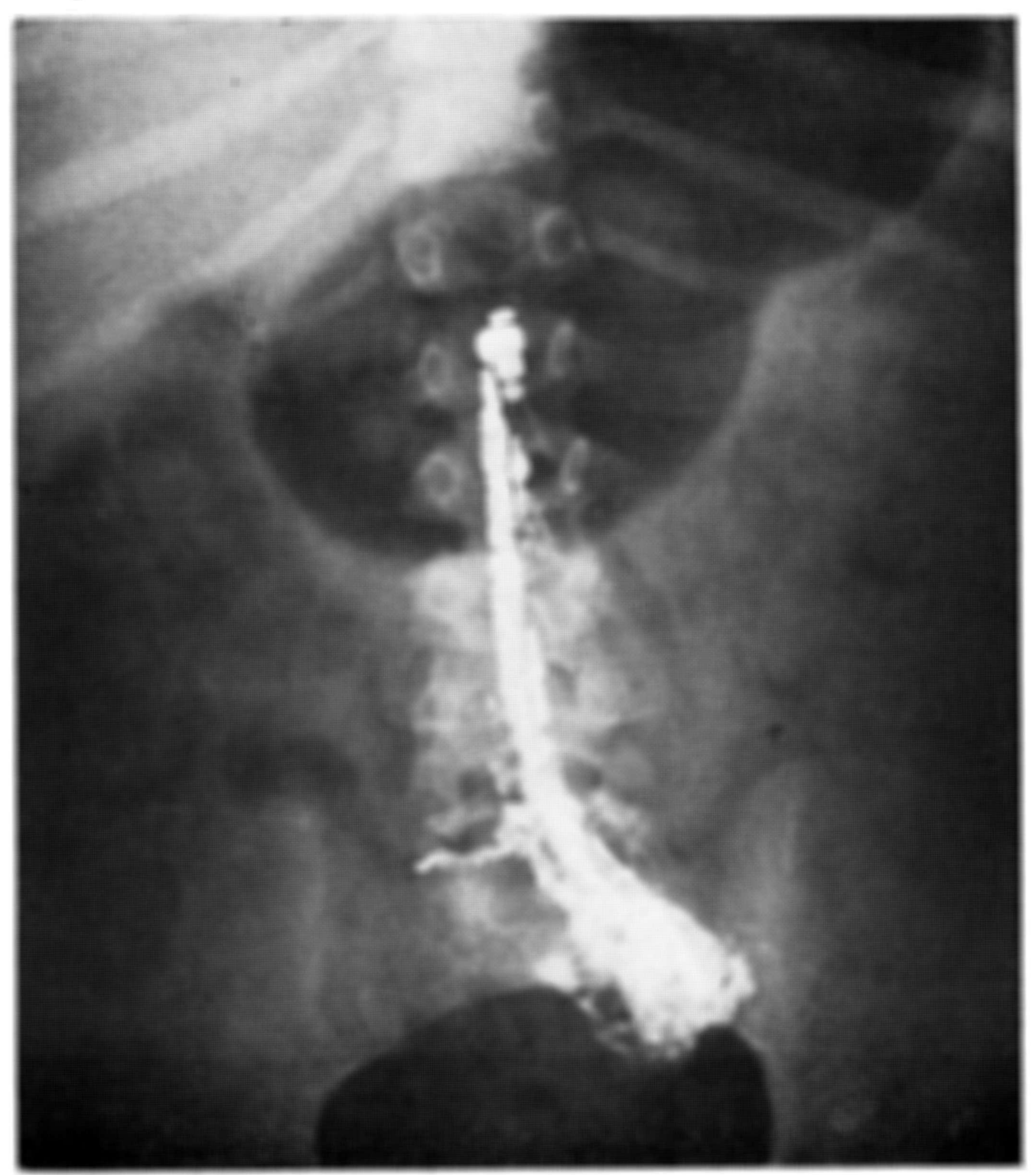

Fig. 2 - Caso C.R.S. - Radiografia de coluna vertebral com o doente em posição erecta dias após a siringomielografia direta. Nota-se o escoamento do material de contraste para a cavidade da meningomielocele $e$ para o espaco subaracnóideo.

\section{COMENTARIOS}

Os cistos da medula espinal podem ocorrer como dilatação do canal central da medula associado a traumatismo medular ${ }^{\mathbf{5} .28}$, insuficiência circulatória medular ${ }^{1}$, tumores medulares ${ }^{13}$, anomalias congênitas do tubo neural 7 e aracnoidite basal 3. Alguns autores usaram os termos siringomielia e hidromielia indistintamente, para denominar as cavidades congênitas intramedulares. Há motivos para se considerar a siringomielia e a hidromielia como entidades patogênicas e histopatológicas distintas 16,17. Na hidromielia há dilatação anormal do canal central da medula espinal, que pode se estender por distàncias variadas entre o IV ventrículo e o cone medular ${ }^{32}$. Suas paredes são revestidas por células ependimárias e o conteúdo é constituido por material semelhante ao LCR ${ }^{14}$. A siringomielia é considerada um divertículo do canal central da medula espinal 
consequente à hiperdistensão e rotura do epêndima $1,8,16$ que o reveste pelo líquido nele contido. A parede da cavidade é constituída por tecido de natureza glial 8 .

Balantine 4 sugere que o termo siringohidromielia é válido, do ponto de vista prático, porque evita confusões quando a distinção entre as duas entidades é difícil. A frequente associação de meningomielocele com hidromielia tem sido notada há muito ${ }^{24}$. A comunicação do canal central da medula espinal com o IV ventrículo tem sido demonstrada por meio da injeção de contraste radiopaco no interior do saco meningocélico 2 nestes doentes.

Apesar do reconhecimento clínico de hidromielia e da siringomielia e de sua eventual associação com processos inflamatórios, traumáticos e vasculares, a origem dessas entidades ainda constitui um enigma ${ }^{1 .}$ Apesar de opiniões contrárias ${ }^{33}$ acredita-se que a siringomielia resulta de distúrbio do fechamento do canal central da medula espinal, por obstáculo de drenagem do LCR do IV ventrículo para o espaço subaracnóideo ${ }^{17}$. Gardner 38 admite também que as forças hidrodinâmicas presentes em casos de hidrocefalia congênita podem atuar sobre o canal central da medula espinal, resultando no aparecimento da meningomielocele.

A seringomielia apresenta padrão clínico típico, na maioria dos casos, e caracteriza-se pela dissociação da sensibilidade em que há comprometimento segmentar bilateral das sensibilidades térmica e dolorosa e preservação das sensibilidades táctil e profunda ${ }^{22,21,29}$. O comprometimento associado das células das pontas anteriores pode acarretar quadro do tipo neurônio-motor inferior e a compressão dos tratos córtico-espinais origina quadros do tipo neurônio-motor superior em segmentos distais. A distribuição das cavidades pode produzir uma constelação de sintomas e sinais bastante variada, que foge à descrição original e clássica. Malformações associadas (síndrome de Arnold-Chiari, diastematomielia, fusão de vértebras cervicais) são comuns, motivo pelo qual a doença é considerada pertencente ao chamado "status disraficus". A evolução do quadro é lenta na maioria das vezes ${ }^{13}$.

Deficit neurológico progressivo tem sido observado em doentes com mielodisplasia ${ }_{19,20,31}$. Tal quadro é explicado como resultante da tração ou da compressão da medula espinal por lipomas e aderências ${ }^{19,31}$, desenvolvimento de gliose com cavitação 39 ou descompensação de hidrocéfalo associada. $O$ fato de a sindrome neurológica nem sempre remitir com a liberação cirúrgica da medula espinal ${ }^{31}$ mas sim após o tratamento da siringomielia ${ }^{20}$, sugere que esta deve ser responsável pela deterioração neurológica de muitos destes doentes. O bloqueio operatório do óbex permitiu remissão da sindrome neurológica do caso ora apresentado, possivelmente por impedir que as forças hidrodinâmicas transmitidas ao canal central da medula espinal causassem lesão medular progressiva ${ }^{16,18}$.

As radiografias simples do crânio e da coluna cervical podem demonstrar alargamento do canal vertebral, anormalidade da transição occipito-cervical, 
escoliose de coluna vertebral, fusões vertebrais e outras malformações dos corpos vertebrais 15,22 .

A perimielografia com contraste radiopaco é útil para revelar a presença de herniação das tonsilas cerebelares ${ }^{15}$. Pode mostrar variação de tamanho da medula conforme a posição do doente ${ }^{15,30}$ ou sinais de aracnoidite 5 . A perimielografia gasosa foi uma grande conquista para o diagnóstico da siringomielia e da hidromielia. Permite demonstrar a presença do assim chamado cisto flácido, ou seja, o colapso da medula espinal cervical quando o doente é colocado na posição erecta 8,9,12,13,15,26,43. Entretanto, mesmo em caso de siringomielia, o cisto pode não colabar devido a dificuldades de trânsito de seu conteúdo 22 .

A demonstração direta e absoluta da presença de cavidade siringomiélica intraniedular somente foi possível após o uso da tomografia computadorizada (TC), da siringomielografia e da siringomielografia isotópica. A TC pode revelar a presença de dilatação do canal vertebral cervical e herniação das amigdalas cerebelares. Para demonstração da cavidade siringomiélica é necessária a combinação da $\mathrm{TC}$ com a cisternografia com contraste radiopaco hidrossolúvel 1,127,36.

A introdução direta de contraste isotópico no interior da cavidade siringomiélica foi padronizada por Ellertson 12,14. Este método permite avaliar a dinâmica do líquido da cavidade siringomiélica ${ }^{26}$. A mobilização indireta do material radioativo para o interior do cisto também pode ser realizada colocando 0 isótopo nos ventrículos ${ }^{54}$, ou no espaço subaracnóideo mediante punção lombar 14,23. Ellertson ${ }^{14}$ propõe também a injeção intratecal de fluoresceína, e a medida de sua concentração na cavidade do cisto siringomiélico.

A siringohidromielografia é, entretanto, o mais preciso método de diagnóstico de certeza da siringomielia e da hidromielia, permitindo a distinção entre as duas entidades. A siringomielografia direta com contraste radiopaco foi descrita pela primeira vez por Vitek em $1928{ }^{40}$. Consiste na introdução do contraste diretamente na cavidade medular siringomiélica, por via percutânea ou a céu aberto. Desde o relato original poucos autores têm feito referência ao uso deste método para o diagnóstico e para acompanhamento dos doentes com siringomielia. A administração acidental de contraste no interior da cavidade medular foi descrita, por alguns, durante a realização de perimielografia lombar 22. A introdução proposital de contraste radiopaco no interior do canal siringomiélico, por via percutânea $5,14,26$, ou durante atos operatórios 23,37 tem tido alguns defensores. Westberg ${ }^{42}$, em 1966 , descreveu pela primeira vez método de injeção de ar diretamente no interior do cisto siringomiélico, mediante punção percutânea cervical ou cérvico-torácica, com o doente em posição deitada. Tal procedimento foi utilizado por poucos autores ${ }^{14}$. Booth 6 recomenda a introdução de mistura de ar e contraste lipossolúvel na cavidade siringomiélica. Logue 26 considera que o uso de contraste lipossolúvel é preferivel ao ar, porque permite melhor delineação do cisto e de suas projeções laterais, e permanece mais tempo permitindo o controle do tratamento. A siringohidro- 
mielografia indireta é de descrição recente e consiste de mobilização de contraste para o interior do cisto siringomiélico através do pertuito que o comunica com a cavidade do IV ventrículo. O contraste pode ser introduzido durante iodoventriculografia $7,10,15,22,30,34,37$, mobilizado do espaço subaracnóideo perirraquiano para o IV ventrículo, durante estudo perimielográfico ${ }^{23}$, ou introduzido no IV ventrículo diretamente durante atos operatórios ${ }^{38}$. Havendo comunicação entre o IV ventrículo e a cavidade siringomiélica e sendo as condições favoráveis ao trânsito do contraste, êle fluirá do IV ventrículo para a cavidade medular. McRae e Staden so sugerem que a ventriculografia, com a demonstração de comunicação franca entre o IV ventrículo e o cisto medular, constitui um critério de diagnóstico diferencial importante entre hidromielia e siringomielia. $O$ aspecto radiográfico da siringomielia é o de uma cavidade com constrições múltiplas e irregulares, que se estende por quase toda a extensão da medula espinal (Figs. 1 e 2). $O$ aspecto final tem sido comparado com moedas empilhadas ou salsichas. Harwood-Nash e Fitz ${ }^{22}$ acreditam que as constrições visíveis ao exame radiológico resultam da presença de feixes de fibras gliais, dispostas transversal e circunsferencialmente ao longo da cavidade siringomiélica. Segundo estes autores a cavidade da hidromielia tem aspecto diferente, pois seus contornos sâo regulares. Logue 26 acredita que o aspecto de moedas empilhadas é devido à tração da medula espinal pelos ligamentos denteados.

Vitek 41 descreveu melhora clínica dos doentes com siringomielia após a punção dos cistos e recomenda tal medida como método terapêutico paliativo. A punção diagnóstica e terapêutica dos cistos medulares tumorais foi descrita por Westberg 42 que recomendava tal procedimento apenas em casos em que a massa intramedular fosse cística. Quencer e col. ${ }^{35}$ foram os primeiros a descrever a punção de tumores medulares císticos não flutuantes. Poucos autores têm realizado punções percutâneas de cistos medulares com finalidade terapêutica $6,25,35$. Entretanto, é conceito generalizado que a melhora clínica é mais duradoura e mais frequente nos cistos tumorais medulares, sendo rara e fugaz em cistos siringomiélicos $6,13,14,25,35$ como observado no caso ora relatado.

A siringomielografia é, portanto, o procedimento neurorradiológico mais preciso para o diagnóstico da siringomielia. Além de avaliar a extensão da cavidade, permite o controle do resultado do tratamento cirúrgico e, quando típica, permite $o$ diagnóstico diferencial dessa entidade com a hidromielia $e$ com tumores císticos ${ }^{22}$. A punção percutânea dos cistos medulares permite também a coleta de material para análise bioquímica, citológica e bacteriológica e pode em alguns casos causar alívio temporário da sintomatologia dos doentes.

RESUMO

É relatado o caso de doente de $\mathbf{5}$ anos de idade, com siringomielia no qual a administração de contraste, destinado a exame perimielográfico, foi realizado incidentalmente, no interior da cavidade siringomiélica. São considerados alguns aspectos relativos aos métodos diagnósticos dessa entidade. 


\section{SU'MMARY}

\section{Syringomyelography: a case report.}

The radiological findings of syringomyelography are described in a five years old patient who underwent a percutaneous injection of opaque contrast mediun (Lipiodol) into the intraspinal syringomyelic cavity. The clinical picture, the usual diagnostic methods and the place of syringomyelography for the diagnosis of syringomielia are discussed.

\section{REFERENCIAS}

1. ABOULKER, J. - La syringomyélie et les liquides intra-rachidiens: syringomyélie, deux conceptions. Neurochirurgie 25, supp 1:9, 1979.

2. ANDERSON, H.; CARLSSON, C. A. \& ROSENGRAN, K. - A radiological study of the central canal in the meningomyelocele. Med. Child. Neurol. 13:96, 1967.

3. APPLEBY, A.; BRADLEY, W. G.; FOSTER, J. B.; HANKINSON, J. \& HUDGSON, P. - Syringomyelia due to chronic aracnoiditis at the foramen magnum. J. Neurol. Sci. 8:451, 1969.

4. BALlaNTINE, H. T. Jr.; OJEMAN, R. G. \& DREW, J. H. - Syringohydromielia. Prog. Neurol. Surg. 4:227, 1971.

5. BARNETT, H. J. M. \& JOUSSE, A. T. - Syringomyelia as late sequel to traumatic paraplegia in quadriplegia: clinical features in syringomyelia. In Syringomyelia - H. J. M. Barnett, J. B. Foster \& P. H. Hudgson, editores. W. B. Saunders Co. Ltd., London-Philadelphia-Toronto, 1973, cap. 10, pgs. 129-153.

6. BOOTH, A. E. \& KENDALL, B. E. - Percutaneous aspiration of cystic lesions of the spinal cord. J. Newrosurg. 33:140, 1970.

7. CHATEL, M.; ODER, J.; SACRABIN, J. M.; SABOURAUD, O.; PECKER, J. \& SIMON, J. - Le syndrome syringomyélie. Rev. Neurol. (Paris): 128-172, 1973.

8. CONWAY, L. W. - Hdrodynamic studies in syringomyelia. J. Neurosurg. 27:501, 1967.

9. CUSICK, J. F.; HAUGHTON, V. M. \& WILLIAMS, A. L. - Radiological assessment of intramedullary spinal cord lesions. Neurosurgery. 4:216, 1979.

10. DEBRUN, G.; DOYON, D.; LEFEBVRE, J. \& LEPINTRE, J. - Opacification fortuite du canal ependimaire lors d'une iodoventriculographie. Prèsse Méd. $72: 239,1964$.

11. DICHIRO, G.; AXEELBAUM, S. P.; SCHALLINGER, D.; TWIGG, H. L. \& LEDLEY, R. S. - Computerized axial tomography in syringomyelia. N. Engl. J. Med. $292: 13$, 1975.

12. ELLERTSSON, A. B. - Semiological diagnogis of syringomyelia related to roentgenologic findings. Acta. Neurol. Scand. 45:385, 1969.

13. ELLERTSSON, A. B. - Syringomyelia and other cystic spinal cord lesions. Acta Neurol. Scand. 45:403, 1969.

14. ELLERTSSON, A. B. \& GREITZ, T. - Myelocystographic and fluorescein studies to demonstrate comunication between intramedullary cysts and CSF space. Acta Neurol. Scand. 45:418, 1969. 
15. FOSTER, J. B. \& HUDGSON, P. - The radiology of comunicating syringomyelia. In Syringomyelia - H. J. M. Barnett, J. B. Foster \& P. H. Hudgson, editores. W. B. Saunders Co. Ltd., London-Philadelphia-Toronto, 1973, cap. 5, pgs. 50-63.

16. GARDNER, W. J. \& ANGEL, J. - The mechanism of syringomyelia and its surgical correction. Clin. Newrosurg. 6:131, 1958.

17. GARDNER, W. J. - Hydrodynamic mechanism of syringomyelia: its relationship to myelocele. J. Neurol. Neurosurg. Psychiat. (London) 28:247, 1965.

18. GARDNER, W. J. - Myelocele: rupture of the neural tube? Clin. Neurosurg. $15: 57,1968$.

19. GROFF, R. A. \& YASKIN, J. C. - Late occurence of sphincter and other neurological disturbances associated with congenital malformation of the vertebral column. Trans. Am. Ne: rol. Assoc. 72:218, 1947.

20. HALL, P. V.; CAMPBELL, R. L. \& KELBECK, J. E. - Meningomyelocele and progressive hydromyelia: progressive paresis in myelodisplasia. $J$. Neurosirg. $43: 457,1975$.

21. HANKINSON, J. - Proceedings: report on 100 cases of syringomyelia. J. Neurol. Neurosurg. Psychiat. (London) $38: 412,1975$.

22. HARWOOD-NASH, D. C. \& FITZ, C. R. - Myelography and syringohydromyelia in infancy and childhood. Radiology 113:661, 1974.

23. HEINZ, E. R.; SCHLESINDER, E. B. \& POTTS, D. G. - Raliologic signs of hydromyelia. Radiology $86: 311,1966$.

24. KEILLER, V. H. - A contribuition to the anatomy of spina bifida. Brain 45:31, 1922.

25. KENDALL, B. \& SYMON, L. - Cyst puncture and endomyelography in cystic tumors of the spinal cord. British J. Radiol. 46:198, 1973.

26. LOGUE, V. - Syringomyelia: a radiodiagnostic and radioterapeutic saga. Clin. Radiol. $22: 2,1971$.

27. MANALFE, C.; GUIRAUD, B.; ESPAGNO, J. \& RESCOL, A. - Computerized cisternography with nietrizamide. Rev. Neurol. (Paris) 134:471, 1978.

28. MARTIN, C. \& MAURY, M. - Syndrome syringomyélique aprés paraplégie tra matique. Prèsse Méd. $72: 2839,1964$.

29. MCIBOY, W. C. \& RICHARDSON, J. C. - Syringomyelia: a clinical review of 75 cases. Canad. Med. Ass. J. 93:731, 1965.

30. MCRAE, D.; DONALD, L. \& STANDEN, J. - Roentgenologic findings in syringomyelia and hydromyelia. Am. J. Roentgen. 98:695, 1966.

31. MATSON, D. D. - Congenital spinal defects. Clin. Neurosurg. 8:185, 1969.

32. NETSKY, M. G. - Syringomvelia: a clinico-pathologic study. Arch. Neurol. Psychiat. (Chicago) 70:741, 1953.

33. OSAKA, K.; TANIMURA, T.; HIRAYAMA, A. \& MATSUMOTO, S. - Myelomeningocele before birth. J. Neurosurg. 49:711, 1978.

34. PESERICO, L.; ANGIERI, P.; MERLI, G. A.; SONNINOV, V.; FAGLIONI, F. \& CANOSSI. G. C. - Combined isotope ventriculography and lumbar myelocysternography in the diagnosis of communicating syringomyelia. J. Neurosurg. 45:576, 1976.

35. QUENCER, R. M.; TENNER, M. A. \& ROTHMAN, L. - Percutaneo:-s spinal cord puncture and myelocystography. Radiology 118:637, 1976. 
36. RESJO, I. M. - Computed tomographic metrizamide myelography in syringohydromyelia. Radiology 131:405, 1979.

37. TJADEN, R. J.; ESTHIER, R.; VEZINA, J. L.; MELENÇON, D. - Iodoventriculography in hydromyelia. J. Canad. Ass. Radiol. 20:265, 1969.

38. TRILLET, M.; JOYEUX, O.; LAPRAS, C.; SCHOTT, B. \& GIRARD, P. F. Syndromes medullaires non syringomyéliques et deformité de Chiari. Rev. Neurol. (Paris) 134:507, 1978.

39. TURNBULL, F. A. - Syringomyelia: complications of spina bifida. Brain: $56: 304$, 1933.

40. VITEK, J. - La punction dorsale thérapeutique et diagnostique des cavités syringomyéliques. Bruxelles Med. 9:311, 1928.

41. VITEK, J. - Nouvelle methode de decompressure et evacuatrice de la cavité syringomyelique par punction faite a son pole inferieu:. Prèsse Méd. 80:1-8, 1932.

42. WESTBERG, G. - Gas myelography and percutaneous puncture in the diagnosis of spinal cord cysts. Acta Radiol. suppl. 252:1-67, 1966.

43. WICKBOM, J. \& HANAFEE, W. - Soft tissue masses immediately below the foramen magnum. Acta Radiol. 1:647, 1963.

Clinica Neurologica - Faculdade de Medicina da USP - Caixa Postal s0657 01000 São Paulo, SP - Brasil. 